\title{
Frecuencia de microsporidiosis intestinal en pacientes positivos para VIH mediante las técnicas de Gram cromotropo rápido y PCR
}

\author{
Jorge H. Botero ${ }^{1,3}$, Martha Nelly Montoya ${ }^{1,3}$, Adriana Lucía Vanegas ${ }^{3}$, \\ Abel Díaz ${ }^{2}$, Luis Navarro-i-Martínez ${ }^{4}$, Fernando Jorge Bornay ${ }^{4}$, Fernando Izquierdo ${ }^{5}$, \\ Carmen del Águila ${ }^{5}$, Sonia del Pilar Agudelo 1,3 \\ ${ }^{1}$ Departamento de Microbiología y Parasitología, Facultad de Medicina, Universidad de Antioquia, Medellín, \\ Colombia. \\ ${ }^{2}$ Centro de Investigaciones Médicas, Facultad de Medicina, Universidad de Antioquia, Medellín, Colombia. \\ ${ }^{3}$ Grupo Interdisciplinario para el Estudio de las Parasitosis Intestinales, Corporación Académica para el \\ Estudio de las Patologías Tropicales, Universidad de Antioquia, Medellín, Colombia. \\ ${ }^{4}$ División de Parasitología, Universidad Miguel Hernández, Elche (Alicante), España. \\ ${ }^{5}$ Sección de Biología Animal y Parasitología, Universidad de San Pablo, Madrid, España. \\ Los microsporidios son protozoos intracelulares obligados, implicados en procesos de diarrea \\ persistente en pacientes con sida, aunque no son exclusivos de este grupo de pacientes. La \\ prevalencia de microsporidios en diferentes países varía entre $8 \%$ y $52 \%$. En nuestro medio no \\ se conoce su frecuencia, por lo que este trabajo se propuso determinar la frecuencia de \\ microsporidiosis intestinal en pacientes positivos para $\mathrm{VIH}$, mediante la prueba del Gram \\ cromotropo rápido (quick hot Gram) y la PCR; para esto se realizó un estudio prospectivo, \\ descriptivo, con una población intencional de todos los pacientes positivos para VIH remitidos \\ al Laboratorio del Grupo Interdisciplinario para el Estudio de las Parasitosis Intestinales por \\ las diferentes instituciones de atención de pacientes positivos para VIH de Medellín en el \\ periodo comprendido entre agosto de 2001 y septiembre de 2002. Se hizo una encuesta \\ clínico-epidemiológica y se practicaron análisis coprológicos seriados que incluían examen \\ directo, por concentración y tinciones especiales para coccidias y microsporidios intestinales; \\ además, se solicitó recuento de linfocitos TCD4+ y carga viral. \\ Se estudiaron 103 pacientes en edades comprendidas entre 2 y 74 años; el 70\% (72/103) \\ presentaba diarrea al ingreso al estudio; la mayoría $(83,5 \%)$ fueron hombres. La frecuencia \\ global de microsporidiosis intestinal fue de 3,9\% (4/103); se encontraron tres pacientes positivos \\ para Enterocytozoon bieneusi y uno con Encephalitozoon intestinalis; otras parasitosis \\ intestinales representaron el $39,8 \%$. La frecuencia de microsporidiosis en este estudio fue \\ relativamente baja; además, como era de esperarse, la mayoría de los casos de microsporidios \\ estuvieron asociados con diarrea prolongada y recuentos de LTCD4+ menores de $100 \mathrm{cél} / \mu \mathrm{l}$ y \\ cargas virales superiores a 100.000 copias (3/4).
}

Palabras clave: VIH, microsporidiosis/epidemiología, diagnóstico, coloración quick hot Gram cromotropo, PCR.

Frequency of intestinal microsporidian infections in HIV-positive patients, as diagnosis by quick hot Gram chromotrope staining and PCR

Microsporidia are intracellular obligate parasites, today mainly associated with diarrhea in AIDS patients. Microsporidia prevalence ranges from $8 \%$ to $52 \%$ in different countries, as evaluated by several diagnostic methods, such as the stain test and PCR. In Medellin, Colombia, its frequency is unknown, and hence, a study was undertaken to determine the frequency of intestinal microsporidiosis in HIV patients, by means of the quick-hot Gram chromotrope test and the PCR. A prospective and descriptive study of an intentional population of all HIV-positive patients was sent to the Grupo Interdisciplinario para el Estudio de las Parasitosis Intestinales laboratory by institutions treating the HIV-positive patients of Medellín between August 2001 
and September 2002. The clinical-epidemiological survey included a serial stool test with direct concentration and special stains for coccidiae and intestinal microsporidia. In addition, counts of lymphocytes TCD4+ and viral load were requested. One hundred and three patients with ages ranging from 2-74 years were evaluated. Seventy percent presented with diarrhea mostly in men (83.5\%). The overall frequency of intestinal microsporidiosis was $3.9 \%$ and that of other intestinal parasitic infections was $39.8 \%$. Three of the four patients positive for microsporida were infected with Enterocytozoon bieneusi and one with Encephalitozoon intestinalis. The microsporidiosis frequency was relatively low with 3 of the 4 cases associated with protracted diarrhea, counts of LTCD4+ below $100 \mathrm{cel} / \mu \mathrm{l}$ and viral loads up to 100.000 copies.

Key words: human immunodeficiency viruses, microsporidiosis/epidemiology, diagnostic, quickhot Gram chromotrope staining, PCR.

En la actualidad, la microsporidiosis se considera de distribución cosmopolita; el número de casos reportados se ha incrementado notoriamente y se han documentado casos en individuos de los cinco continentes, la mayoría de éstos, enfermos infectados con el virus de la inmunodeficiencia humana $(\mathrm{VIH})(1,2)$.

Existen diferentes series clínicas en las que se reportan frecuencias variables de microsporidiosis (3-5); sin ser una infección exclusiva del hospedero inmunocomprometido grave (6), la mayor prevalencia se observa en estos pacientes. Los estudios de Europa y Estados Unidos han revelado cifras entre el $6 \%$ y el $60 \%$ en este mismo grupo de pacientes (2).

Aunque en Colombia se han diagnosticado casos aislados, no se conoce la prevalencia real de esta enfermedad; hasta la fecha, sólo existe un estudio sistematizado realizado en Bogotá en el que se encontró una prevalencia de microsporidiosis intestinal de 3,5\% en pacientes positivos para $\mathrm{VIH}$, utilizando técnicas de tinción (7). Quizá la ausencia de un método diagnóstico efectivo para la identificación de los microsporidios limita la búsqueda, lo que dificulta establecer diagnósticos etiológicos en infecciones subclínicas y clínicas, además de no permitir un manejo adecuado y racional de los pacientes, especialmente, los positivos para VIH que consultan por procesos diarreicos prolongados a los cuales no se les reconoce la causa de su proceso y, por tanto,

Correspondencia:

Jorge H. Botero

jbotero@quimbaya.udea.edu.co

Recibido: 10/06/04; aceptado: 09/09/04 su tratamiento y manejo no son los más convenientes.

Debido a que las esporas de los microsporidios son muy pequeñas, 1 a $2 \mu \mathrm{m}$, el diagnóstico por laboratorio inicialmente se basó en su detección en las biopsias intestinales por medio del uso de la microscopía electrónica. Sin embargo, esta técnica es invasiva, poco sensible y costosa. Posteriormente, se emplearon diferentes métodos de tinción como la tricrómica modificada por Weber $(8,9)$, pruebas fluorescentes con fluorocromos como el uvitex o el blanco de calcoflúor $(10,11)$ y, más recientemente, la prueba del Gram cromotropo rápido (quick-hot Gram) $(11,12)$ con resultados comparables en cuanto a sensibilidad, especificidad y valores predictivos entre estas diferentes pruebas, las cuales son muy útiles en el diagnóstico inicial de la microsporidiosis intestinal. Sin embargo, es importante resaltar que las pruebas por tinción son incapaces de realizar diferenciación de especie, la cual sólo es posible mediante la microscopía electrónica, la inmunofluorescencia con anticuerpos monoclonales o la reacción en cadena de la polimerasa $(P C R)(9,13-$ 29).

La diferenciación de especie constituye un hecho deseable para un mejor abordaje terapéutico de los pacientes, al igual que permite un manejo más racional. Además, se debe establecer la especie con el propósito de conocer la epidemiología real de cada uno de los microsporidios implicados en infecciones del tracto gastrointestinal, lo cual redunda en un mejor conocimiento de esta infección parasitaria; por estas razones, se hace indispensable realizar el diagnóstico general de 
la microsporidiosis intestinal y, posteriormente, la identificación de la especie implicada.

La microsporidiosis puede ser más frecuente de lo estimado hasta el momento, por lo cual se hizo necesario en nuestro medio desarrollar un trabajo coordinado para establecer la frecuencia de microsporidiosis intestinal en pacientes positivos para VIH e implementar la técnica por coloración denominada Gram cromotropo rápido (quick hot Gram) y PCR para el diagnóstico global de microsporidiosis e identificación de especie, respectivamente $(11,12)$.

\section{Metodología}

El estudio fue prospectivo, descriptivo, de prevalencia o corte transversal.

\section{Población y muestra}

La población fue intencional de todos los pacientes de Medellín positivos para VIH remitidos al Laboratorio del Grupo Interdisciplinario para el Estudio de las Parasitosis Intestinales por las diferentes instituciones de atención de pacientes positivos para $\mathrm{VIH}$ en el período comprendido entre agosto de 2001 y septiembre de 2002, la cual incluyó 103 pacientes remitidos.

A cada paciente se le aplicó una encuesta clínicoepidemiológica que incluía las variables de edad, sexo, ocupación, grado de escolaridad, procedencia, nivel socioeconómico, condiciones higiénico-sanitarias, convivencia con animales, presencia o ausencia de diarrea, número de evacuaciones y sintomatología gastrointestinal asociada; se anotaron en esta encuesta los resultados del recuento de CD4/ $\mu$ y y la carga viral realizados en la Empresa Prestadora de Servicios de cada uno de los pacientes.

Además, se solicitaron tres muestras de materia fecal con un intervalo interdiario entre cada una de ellas, a las cuales se les realizó examen directo, por concentración, tinciones especiales para coccidias y microsporidios intestinales y PCR.

\section{Tinción de Gram cromotropo rápido (quick- hot Gram)}

Una vez recolectada la muestra de materia fecal, se hizo un extendido fino en placas que se dejaron secar al aire y se fijaron con metanol absoluto (Analyticals, código 414854) durante 5 minutos; luego, se tiñeron con violeta de genciana (Merck, código 32041300) durante 1 minuto y se lavó el exceso de colorante con agua del chorro; las placas se sumergieron en solución de lugol ( $\mathrm{KI}$ al 0,66\%, Merck código 551761, y yodo metálico al 0,33\%, Baker analyzed código 3162-1) durante 1 minuto. El exceso de lugol se retiró por arrastre con una solución decolorante $(50 \mathrm{ml}$ de etanol al 95\%, Merck, código k28410083, y $50 \mathrm{ml}$ de acetona al 5\%, Sigma, código 53406-4).

Posteriormente, se lavaron con agua del chorro para retirar el residuo de solución decolorante e, inmediatamente, se tiñeron así: se sumergieron las placas en solución de cromotropo (cromotropo 2R al 6\%, Sigma, código c-3143; fast green FCF al $0,15 \%$ (Sigma, código F7258), ácido fosfotúngstico al 0,7\% (Sigma, código P4006), y ácido acético glacial al 3\%, vol/vol (Sigma, código F6005) durante 5 minutos; se decolorararon con alcohol ácido (ácido acético glacial al 4,5\%, vol/ vol, y etanol al $90 \%$ a una concentración final del $95,5 \%$, vol $/ \mathrm{vol}$ ) durante 3 segundos; luego, se deshidrataron con etanol al 95\% durante 1 minuto; se repitió este paso dos veces, empleando alcohol etílico puro y, finalmente, se dejaron secar y se montaron las placas con Entellan ${ }^{\mathrm{MR}}$ (Merck, 6302603); se leyeron en microscopio de luz a mil aumentos.

\section{Reacción en cadena de la polimerasa}

Hasta la extracción, las muestras de materia fecal se conservaron congeladas a $-20^{\circ} \mathrm{C}$ en etanol puro.

La extracción se realizó siguiendo el método de Da Silva et al. $(14,16)$, utilizando el estuche comercial FastDNA (BIO 101, Inc., Vista, California); para la purificación del ADN eluido se empleó el estuche QIAquick PCR purification (Quiagen Inc., Santa Clarita, California); por medio de este método se optimizó la recuperación de ADN, se minimizó la presencia de inhibidores de la PCR y se redujo significativamente el tiempo empleado en cada muestra procesada.

Las regiones SSU-ARNr (subunidad pequeña del ARN ribosómico) de los microsporidios se amplificaron utilizando cebadores específicos para Encephalitozoon intestinalis, SINTF 5'TTTCGAG 
TGTAAGGAGTCGA3', cuya posición en la secuencia es de 362 a 382 y SINTR 5'CCGTCCTCGTTCTCCTGCCCG3', posición 861 a 881 , que amplifican un producto de 520 pb (número de acceso al GeneBank UD9929); y para Enterocytozoon bieneusi, EBIEF15'GAAACTTGTCC ACTCCTTACG3', cuya posición en la secuencia es 295 a 315 y EBIER1 5'CCATGCACCACTCCTG CCATT3', posición 881-901, con un producto de amplificación de 607 pb (número de acceso al GeneBank L16868)(15). Para la mezcla de la reacción se utilizaron $28,75 \mu$ l de agua desionizada estéril, $5 \mu \mathrm{l}$ de tampón 10X (Perkin Elmer, 100 $\mathrm{mM}$ Tris- $\mathrm{HCl}, 500 \mathrm{mM} \mathrm{KCl}, 15 \mathrm{mM} \mathrm{MgCl}$, gelatina 0,01\%), $4 \mu \mathrm{l}$ de desoxinucleótidos trifosfatados (Perkin Elmer) a una concentración final de 1,25 $\mathrm{mM}$ cada uno, $1 \mu \mathrm{l}$ de cada uno de los iniciadores ( $F$ y $R$ ), $0,25 \mu$ de AmpliTAQ polimerasa (Perkin Elmer), $10 \mu \mathrm{l}$ de ADN extraído, para un volumen final de $50 \mu$ l.

Las reacciones se llevaron a cabo en un termociclador GeneAmp PCR System 9600 (Perkin Elmer Cetus, Norwalk, Conneticut, U.S.A.) en sistema de microplaca. Las condiciones de reacción de la PCR fueron: desnaturalización a $94^{\circ} \mathrm{C}$ durante 30 segundos en todos los casos, anillado a $45^{\circ} \mathrm{C}$ para los iniciadores de $E$. intestinalis, y para $E$. bieneusi, a $55^{\circ} \mathrm{C}$ durante 30 segundos y la extensión a $72^{\circ} \mathrm{C}$ durante 90 segundos. En todos los casos se realizaron 35 ciclos. Se añadió un control positivo en todas las reacciones realizadas, que consistió en ADN de $E$. intestinalis o $E$. bieneusi en la PCR correspondiente, para cada uno de estos microsporidios y como control negativo se agregó agua destilada.
EI ADN amplificado se separó mediante electroforesis con gel de agarosa al $2 \%$ en un tampón tris 0,01 M, ácido bórico 0,09 M y EDTA $0,001 \mathrm{M}$, a pH de 8,4 (Sigma), teñido con bromuro de etidio y se visualizó mediante luz UV.

Los datos se tabularon en el programa Excel y el análisis estadístico se realizó en Epi-Info 6.0. Se analizaron variables demográficas (edad, sexo, ocupación, grado de escolaridad, procedencia, nivel socioeconómico, condiciones higiénicosanitarias y convivencia con animales), clínicas y de laboratorio.

Aunque este estudio no presentaba ningún riesgo para el paciente, a cada uno se le sometió a consideración el consentimiento informado para su firma, en el cual se le daba a conocer en términos entendibles, los fines, la pertinencia y la naturaleza del estudio, acogiéndose a las normas acerca de aspectos éticos de investigación en humanos de la Resolución 008430 del Ministerio de Salud.

\section{Resultados}

Se estudiaron 103 pacientes positivos para $\mathrm{VIH}$, con edades comprendidas entre 2 y 74 años, la mayoría $(74,8 \%)$, como era de esperarse, en edad reproductiva. Del total de pacientes incluidos, el $70 \%$ presentaba diarrea al ingreso al estudio; la mayoría $(83,5 \%)$ fueron hombres (cuadro 1 ).

\section{Tinción de Gram cromotropo rápido (quick- hot Gram) y PCR}

De los pacientes evaluados por la tinción de Gram cromotropo rápido y $\mathrm{PCR}$, cuatro fueron positivos para microsporidiosis intestinal $(3,9 \%)$, con

Cuadro 1. Distribución de los pacientes positivos para VIH por rangos de edad y sexo de acuerdo con la presencia o ausencia de diarrea.

\begin{tabular}{|c|c|c|c|c|c|}
\hline \multirow[t]{2}{*}{$\begin{array}{l}\text { Edad } \\
\text { (años) }\end{array}$} & \multicolumn{2}{|c|}{$\begin{array}{l}\text { Mujeres } \\
\text { Diarrea (\%) }\end{array}$} & \multicolumn{2}{|c|}{$\begin{array}{l}\text { Hombres } \\
\text { Diarrea (\%) }\end{array}$} & \multirow[t]{2}{*}{ N (\%) } \\
\hline & + & - & + & - & \\
\hline $0-4$ & $2(1,9)$ & 0 & $1(0,9)$ & 0 & $3(2,9)$ \\
\hline $5-14$ & 0 & 0 & $2(1,9)$ & 0 & $2(1,9)$ \\
\hline $15-44$ & $12(11,7)$ & $1(0,9)$ & $43(41,8)$ & $21(20,4)$ & $77(74,8)$ \\
\hline $45-60$ & $1(0,9)$ & $1(0,9)$ & $9((8,8)$ & $2(1,9)$ & $13(12,6)$ \\
\hline$>60$ & 0 & 0 & $2(1,9)$ & $6(5,8)$ & $8(7,7)$ \\
\hline Total & $15(14,6)$ & $2(1,9)$ & $57(55,4)$ & $29(28,1)$ & $103(100)$ \\
\hline
\end{tabular}

$\mathrm{N}$ : número absoluto de casos; +: pacientes con diarrea; -: pacientes sin diarrea 
edades de 24, 29, 33 y 35 años. Los cuatro pacientes positivos se detectaron por PCR, aunque por tinción sólo fue positivo uno de ellos (figura 1). Del total de casos de microsporidiosis intestinal, el 75\% (3/4) amplificó con los iniciadores específicos para E. bieneusi (figura 2 A) y el $25 \%$ (1/4) con los de E. intestinalis (figura 2B). Todos los pacientes con $E$. bieneusi presentaron procesos diarreicos persistentes (>14 días), cargas virales superiores a 100.000 copias y recuentos de LTCD4+ inferiores a 100 células/ $\mu$, a diferencia del paciente positivo para $E$. intestinalis que no presentó diarrea y tenía una carga viral de sólo 20.400 copias y un recuento

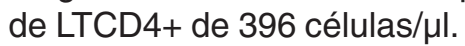

Dado el reducido número de pacientes positivos para microsporidiosis intestinal no se pudieron realizar comparaciones estadísticas entre las variables demográficas. Sin embargo, todos los pacientes positivos para microsporidios fueron del sexo masculino y el $50 \%$ (2/4) relató convivencia con animales.

\section{Otras parasitosis intestinales}

En los 103 pacientes evaluados se obtuvo una frecuencia global de parásitos intestinales de $39,8 \%$, con multiparasitismo de 6,8\% (7/103), distribuidos de la siguiente manera: Cryptosporidium sp. (18,4\%), Entamoeba histolytica/dispar (9,7\%),

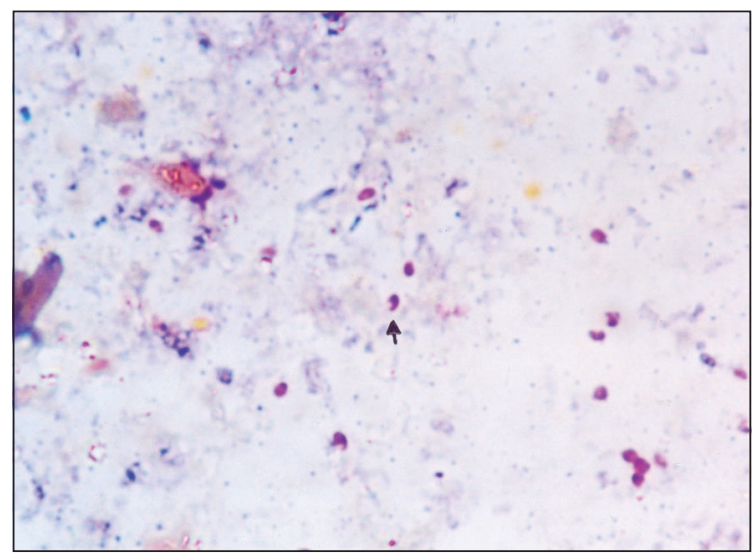

Figura 1. Coloración de Gram cromotropo rápido (quickhot Gram) para microsporidios intestinales. Se observa una muestra positiva para microsporidios intestinales. La flecha señala una espora que toma la coloración violeta pálido; nótese la vacuola posterior y el túbulo polar. Cámara Nikon SDX, optiphot-2, objetivo 100X.

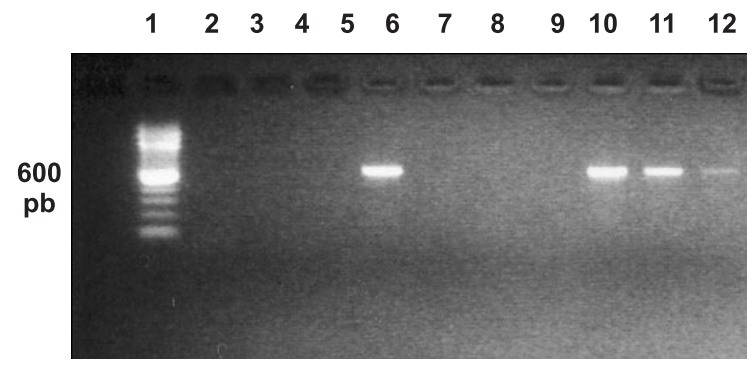

Figura 2. PCR para microsporidios intestinales. A. Amplificación de ADN mediante PCR para E. bieneusi. Carril 1: marcadores de peso molecular; carril 2 y 6 : control negativo y positivo, respectivamente; carriles 3,4 y 7 al 12 : pacientes.

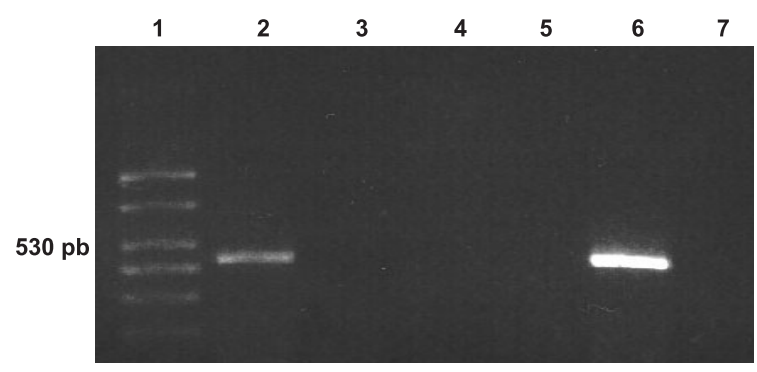

B. Amplificación de ADN mediante PCR para E. intestinalis. Carril 1: marcadores de peso molecular; carril 2 al 5: pacientes; carril 6 y 7 : control positivo y negativo, respectivamente.

Giardia duodenalis (4,0\%), Strongyloides stercoralis (3,9\%), uncinarias $(2,9 \%)$ e Isospora belli, Ascaris lumbricoides y Trichuris trichiura, $1,9, \%$ cada uno.

Los pacientes con microsporidiosis no presentaban otros parásitos intestinales, a excepción de un paciente con E. bieneusi en el que se encontró coinfección con Cryptosporidium $\mathrm{sp}$.

\section{Discusión}

A partir de los primeros informes de microsporidiosis como agentes de infección humana, el número de casos informados se ha incrementado notoriamente hasta el punto que a la infección por microsporidios se le considera de distribución cosmopolita. Hasta la fecha se han documentado casos en individuos de los cinco continentes y la inmensa mayoría son enfermos con sida $(9,30-33)$. 
Existen diferentes series clínicas de Europa, Norteamérica y Latinoamérica, en las que se informan frecuencias variables de microsporidiosis en pacientes con sida y diarrea crónica $(1,9,34-$ 44). La frecuencia de microsporidiosis intestinal encontrada en este estudio (3,9\%) en un período de un año fue relativamente baja, semejante a la de $3,5 \%$ reportada por Flórez et al., cifras comparables con los estudios realizados en países en donde la prevalencia de sida es similar a la de Colombia (32,45-51). En Brasil (48) y Venezuela (52) que son países que presentan tasas más altas de pacientes positivos para $\mathrm{VIH}$, se han informado prevalencias de microsporidiosis de $27,5 \%$ y $50 \%$, respectivamente; por consiguiente, se debe tener en cuenta que a medida que aumenten los casos de sida incrementará, probablemente, la microsporidiosis intestinal en estos pacientes.

E. bieneusi ha sido identificado recientemente en muestras fecales de perros, gatos y cerdos $(53,54)$. Además, E. intestinalis se ha encontrado en diferentes mamíferos $(30,55)$, inclusive hospederos humanos inmunocompetentes $(56,57)$, lo que ha sugerido un origen zoonótico de las infecciones por esta especie; aunque el $50 \%$ de los pacientes positivos para microsporidiosis intestinal en este estudio (2/4) relató convivencia con mascotas, debido al bajo número de casos encontrados no es posible hacer asociaciones estadísticas con respecto a variables clínicoepidemiológicas.

Dada la falta de disponibilidad de pruebas para inmunodiagnóstico, la detección de la infección por microsporidios se basa actualmente en la demostración directa del parásito por medio de las técnicas de coloración (8-13,26,58,59); sin embargo, la sensibilidad y la especificidad son bajas y variables, como se evidenció en este trabajo, en el cual sólo fue posible diagnosticar un paciente por el Gram rápido.

Por otro lado, con las técnicas por tinción no es posible realizar la diferenciación de especie, la cual adquiere importancia clínica dado que el tratamiento varía según se encuentre infección por E. intestinalis o E. bieneusi. En la actualidad, la diferenciación de especie sólo es posible por medio de las técnicas de inmunofluorescencia indirecta que emplean anticuerpos policlonales o monoclonales dirigidos contra cada una de las especies de microsporidios $(8,9,13,60,61)$, o por el uso de la PCR $(9,13-29)$.

La PCR es una técnica rápida, sensible y específica comparada con las técnicas inmunofluorescentes y el Gram rápido $(13,25)$; detecta un umbral de $10^{2}$ esporas por $\mathrm{ml}$ de materia fecal, mientras que la técnica de la coloración del Gram rápido requiere $10^{4}-10^{6}$ esporas $/ \mathrm{ml}$ (8), lo que podría explicar el resultado obtenido en este estudio en el que se encontraron 4 pacientes positivos por PCR y sólo 1 de ellos por la técnica de coloración descrita. Por esta razón, la PCR se constituye en una herramienta diagnóstica atractiva para su empleo bajo condiciones de laboratorio en su uso cotidiano, ya que, a la vez, permite hacer diagnóstico y diferenciación de especie de microsporidios intestinales.

Al analizar los resultados del recuento de LT CD4+ y las cargas virales de los pacientes positivos para microsporidiosis intestinal se encontró que los tres pacientes con E. bieneusi presentaban diarrea, tenían un recuento de LTCD4+ menor de 100 células/ $\mu$ y una carga viral mayor de 100.000 copias, mientras que el paciente con $E$. intestinalis era asintomático, tenía un recuento de LTCD4+ superior a 100 células/ $\mu$ l y una carga viral de 20.400; estos resultados están de acuerdo con lo reportado por diferentes autores con respecto a la asociación entre el proceso diarreico y la disminución de LTCD4+ y el aumento de la carga viral $(9,62)$, lo que debe llamar la atención de los médicos para el seguimiento de los pacientes positivos para VIH con diarrea o sin ella.

Además, es importante destacar que la microsporidiosis en este trabajo fue la cuarta parasitosis en orden de frecuencia, sólo superada por criptosporidiosis, amibiosis y giardiosis, lo cual aunque está de acuerdo con los diferentes estudios en los que la criptosporidiosis es la principal causa de diarrea persistente en pacientes positivos para VIH $(35,38,43,63,64)$, deja vislumbrar la importancia que va adquiriendo la micros-poridiosis en este tipo de pacientes.

Con respecto a otros parásitos intestinales, en este estudio se encontró una frecuencia de 18,4\% 
de Cryptosporidium sp., que concuerda con los diferentes estudios realizados en grupos de pacientes positivos para VIH de Norteamérica, Latinoamérica y Colombia que informan frecuencias entre el $10 \%$ y el $50 \%(7,40,42-$ $44,52,65)$, contrario a lo descrito en individuos inmunocompetentes cuyas frecuencias son un poco menores, del 3\% al $8 \%(52,66-68)$.

Por otro lado, se observó una gran variabilidad con relación a la frecuencia de parásitos intestinales en pacientes positivos para VIH, informados por autores latinoamericanos y colombianos. La frecuencia de $9,7 \%$ para $E$. histolytica/dispar, reportada en este estudio, fue tres y media veces mayor que la encontrada por López et al. (69); sin embargo, estuvo por debajo de la notificada por Flórez et al., del 13\% (7), y otros estudios como el de India de $14,9 \%$ (70). La frecuencia de $G$. duodenalis de $4,0 \%$ fue ligeramente superior a la encontrada en el estudio de Flórez et al. (7), 1,8\%, semejante a la de López et al. (69), 4,7\%, pero relativamente baja comparada con otros estudios como el de India, $8,3 \%$ (70), y Brasil, $16 \%$ (71). En el caso de $S$. stercoralis la frecuencia de $3,9 \%$ reportada fue mucho mayor a la del estudio de López et al., 0,9\% (69), pero similar a la de Flórez et al., 3,5\% (7). Además, es importante señalar que las uncinarias, A. lumbricoides, T. trichiura e I. belli fueron los parásitos con el menor número de casos encontrados, 2,9\% para las uncinarias y $1,9 \%$ para los restantes.

Esta variabilidad en la frecuencia de parásitos intestinales en este grupo de pacientes es de esperar debido a que los estudios se realizaron en áreas geográficas diferentes, en donde las condiciones higiénico-sanitarias son heterogéneas; por tanto, la prevalencia de las parasitosis intestinales en cada uno de estos lugares no es igual. De otro lado, estos trabajos se hicieron en épocas distintas y, además, no se sabe si fueron prescritas terapias profilácticas contra parásitos intestinales por los médicos tratantes o producto de la automedicación por parte del paciente.

En conclusión, la microsporidiosis intestinal está presente en nuestro medio y se podría pensar que puede ser más frecuente a la notificada en este estudio. Hay que considerarla no sólo en hospederos inmunocomprometidos graves, sino también en pacientes asintomáticos positivos para $\mathrm{VIH}$, o con recuentos de LTCD4+ mayores de 100 células $/ \mu \mathrm{l}$, al igual que en pacientes sometidos a trasplantes de órganos $(72,73)$ e, incluso, en individuos inmunocompetentes (74). Por lo tanto, se debe continuar con la búsqueda activa de casos utilizando, además de la prueba del Gram rápido, la PCR la cual nos permite captar un mayor número de casos y, a la vez, determinar la especie involucrada del parásito ( $E$. intestinalis o $E$. bieneusi).

\section{Agradecimientos}

Al Comité para el Desarrollo de la Investigación de la Universidad de Antioquia, por la financiación de este proyecto. A la Dirección General de Relaciones Externas y Cooperación de la Generalitat Valenciana de España por la financiación de las pruebas moleculares. A todos los centros de atención en salud de pacientes positivos para VIH, a la Fundación Positivos por la Vida y la Fundación Eudes y a todos los pacientes que gentilmente participaron en este estudio.

\section{Referencias}

1. Waywa D, Kongkriengdaj S, Chaidatch S, Tiengrim $\mathrm{S}$, Kowadisaiburana $\mathrm{B}$, Chaikachonpat $\mathrm{S}$ et al. Protozoan enteric infection in AIDS related diarrhea in Thailand. Southeast Asian J Trop Med Public Health 2001;32:151-5.

2. Desportes-Livage I. Microsporidia and other opportunistic protozoa in patients with acquired immunodeficiency syndrome (AIDS). Clin Microbiol Infect 1996;1:152-3.

3. Gamboa Domínguez A, Bencosme Vinas C, Kato Maeda M. Microsporidiasis en pacientes con SIDA y diarrea crónica. Experiencia en el Instituto Nacional de la Nutrición "Salvador Zubirán". Rev Gastroenterol Mex 1999;64:70-4.

4. Ramakrishna BS. Prevalence of intestinal pathogens in HIV patients with diarrhea: implications for treatment. Indian J Pediatr 1999;66:85-91.

5. Punpoowong B, Viriyavejakul P, Riganti M, Pongponaratn E, Chaisri U, Maneerat Y. Opportunistic protozoa in stool samples from HIV-infected patients. Southeast Asian J Trop Med Public Health 1998;29:31-4.

6. Leclerc H, Schwartzbrod L, Dei-Cas E. Microbial agents associated with waterborne diseases. Crit Rev Microbiol 2002;28:371-409. 
7. Flórez AC, García DA, Moncada L, Beltrán M. Prevalencia de microsporidios y otros parásitos intestinales en pacientes con infección por VIH, Bogotá, 2001. Biomédica 2003;23:274-82.

8. Weber R, Swartz DA, Deplazes P. Laboratory diagnosis of microsporidiosis. En: Wittner M, editor. The microsporidia and microsporidiosis. Washington, D.C.: ASM Press; 1999. p.315-61.

9. Weber R, Deplazes P, Schwartz D. Diagnosis and clinical aspects of human microsporidiosis. Contrib Microbiol 2000;6:166-92.

10. Didier ES, Orenstein JM, Aldras A, Bertucci D, Rogers LB, Janney FA. Comparison of three staining methods for detecting microsporidia in fluids. J Clin Microbiol 1995;33:3138-45.

11. Ignatius R, Henschel S, Liesenfeld $O$, Mansmann U, Schmidt W, Koppe S et al. Comparative evaluation of modified trichrome and Uvitex 2B stains for detection of low numbers of microsporidial spores in stool specimens. J Clin Microbiol 1997;35:2266-9.

12. Ignatius R, Lehmann M, Miksits K, Regnath T, Arvand M, Engelmann E et al. A new acid-fast trichrome stain for simultaneous detection of Cryptosporidium parvum and microsporidial species in stool specimens. J Clin Microbiol 1997;35:446-9.

13. Bornay-Llinares FJ, da Silva AJ, Moura H, Schwartz DA, Visvesvara GS, Pieniazek NJ et al. Immunologic, microscopic, and molecular evidence of Encephalitozoon intestinalis (Septata intestinalis) infection in mammals other than humans. J Infect Dis 1998;178:820-6.

14. Da Silva AJ, Slemenda SB, Visvesvara GS, Schwartz DA, Wilcox CM, Wallace S et al. Detection of Septata intestinalis (Microsporidia) Cali et al. 1993 using polymerase chain reaction primers targeting the small subunit ribosomal RNA coding region. Mol Diagn 1997;2:47-52.

15. da Silva AJ, Schwartz DA, Visvesvara GS, de Moura H, Slemenda SB, Pieniazek NJ. Sensitive PCR diagnosis of Infections by Enterocytozoon bieneusi (microsporidia) using primers based on the region coding for small-subunit rRNA. J Clin Microbiol 1996; 34:986-7.

16. da Silva AJ, Bornay-Llinares FJ, del Aguila de la Puente C del A, Moura H, Peralta JM, Sobottka I et al. Diagnosis of Enterocytozoon bieneusi (microsporidia) infections by polymerase chain reaction in stool samples using primers based on the region coding for small-subunit ribosomal RNA. Arch Pathol Lab Med 1997; $121: 874-9$

17. Delbac F, Vivares C. A PCR technique for detecting and differentiating known microsporidia in AIDS patients. J Eukaryot Microbiol 1997;44:75S.

18. Dowd SE, Gerba CP, Enriquez FJ, Pepper IL. PCR amplification and species determination of microsporidia in formalin-fixed feces after immunomagnetic separation. Appl Environ Microbiol 1998;64:333-6.

19. Fedorko DP, Nelson NA, Cartwright CP. Identification of microsporidia in stool specimens by using PCR and restriction endonucleases. J Clin Microbiol 1995;33: 1739-41.

20. Fedorko DP, Hijazi YM. Application of molecular techniques to the diagnosis of microsporidial infection. Emerg Infect Dis 1996;2:183-91.

21. Franzen C, Muller A, Hegener P, Salzberger B, Hartmann P, Fatkenheuer G et al. Detection of microsporidia (Enterocytozoon bieneusi) in intestinal biopsy specimens from human immunodeficiency virusinfected patients by PCR. J Clin Microbiol 1995;33: 2294-6.

22. Katzwinkel-Wladarsch S, Lieb M, Helse W, Loscher $\mathbf{T}$, Rinder $\mathbf{H}$. Direct amplification and species determination of microsporidian DNA from stool specimens. Trop Med Int Health 1996;1:373-8.

23. Kock NP, Petersen H, Fenner T, Sobottka I, Schmetz C, Deplazes $\mathbf{P}$ et al. Species-specific identification of microsporidia in stool and intestinal biopsy specimens by the polymerase chain reaction. Eur $\mathrm{J}$ Clin Microbiol Infect Dis 1997;16:369-76.

24. Ombrouck C, Ciceron L, Desportes-Livage I. Specific and rapid detection of Microsporidia in stool specimens from AIDS patients by PCR. Parasite 1996; 3:85-6.

25. Ombrouck C, Ciceron L, Biligui S, Brown S, Marechal P, van Gool T et al. Specific PCR assay for direct detection of intestinal microsporidia Enterocytozoon bieneusi and Encephalitozoon intestinalis in fecal specimens from human immunodeficiency virus-infected patients. J Clin Microbiol 1997;35:652-5.

26. Rinder H, Janitschke K, Aspock H, Da Silva AJ, Deplazes P, Fedorko DP et al. Blinded, externally controlled multicenter evaluation of light microscopy and PCR for detection of microsporidia in stool specimens. J Clin Microbiol 1998;36:1814-8.

27. Weiss LM, Vossbrinck CR. Microsporidiosis: molecular and diagnostic aspects. Adv Parasitol 1998;40:351-95.

28. Weiss LM. Microsporidia: emerging pathogenic protists. Acta Trop 2001;78:89-102.

29. Wolk DM, Schneider SK, Wengenack NL, Sloan LM, Rosenblatt JE. Real-time PCR method for detection of Encephalitozoon intestinalis from stool specimens. J Clin Microbiol 2002;40:3922-8.

30. Deplazes P, Mathis A, Weber R. Epidemiology and zoonotic aspects of microsporidia of mammals and birds. Contrib Microbiol 2000;6:236-60.

31. Bretagne S, Foulet F, Alkassoum W, Fleury-Feith J, Develoux M. Prevalence de spores d'Enterocytozoon bieneusi dans les selles de malades atteints de SIDA et 
dénfants africains ne pas infectés par le VIH. Bull Soc Pathol Exot 1993;86:351-7.

32. Cotte L, Rabodonirina M, Piens MA, Perreard M, Mojon M, Trepo C. Prevalence of intestinal protozoans in French patients infected with HIV. J Acquir Immune Defic Syndr 1993;6:1024-9.

33. Curry A, Canning EU. Human microsporidiosis. J Infect 1993;27:229-36.

34. Goodgame R, Stager C, Marcantel B, Alcocer E, Segura AM. Intensity of infection in AIDS-related intestinal microsporidiosis. J Infect Dis 1999;180:92932.

35. Esfandiari A, Jordan WC, Brown CP. Prevalence of enteric parasitic infection among HIV-infected attendees of an inner city AIDS clinic. Cell Mol Biol (Noisy-le-grand) 1995;41:S19-23.

36. Marangi A, Maggi P, Panaro MA, Angarano G, Pastore G, Lisi $\mathbf{S}$ et al. Intestinal microsporidiosis in AIDS patients with diarrhoeal illness in Apulia (south Italy). New Microbiol 1995;18:435-9.

37. Molina JM, Sarfati C, Beauvais B, Lemann M, Lesourd A, Ferchal F et al. Intestinal microsporidiosis in human immunodeficiency virus-infected patients with chronic unexplained diarrhea: prevalence and clinical and biologic features. J Infect Dis 1993;167:217-21.

38. Wuhib T, Silva TM, Newman RD, Garcia LS, Pereira ML, Chaves CS et al. Cryptosporidial and microsporidial infections in human immunodeficiency virus-infected patients in northeastern Brazil. J Infect Dis 1994;170:494-7.

39. van Gool T, Dankert J. Human microsporidiosis: Clinical, diagnostic and therapeutic aspects of an increasing infection. Clin Microbiol Infect 1995;1:75-85.

40. Bellegarde E, Abuin J, Sirianni B, Ambrogio A. Enteroparásitos en pacientes seropositivos para el virus de la inmunodeficiencia humana: evaluación anual, prevalencia. Rev Argent Infectol 1995;8:9-10.

41. Capó de Paez V, Barreto $B$, Velásquez B, Luzardo C, Martínez A, Alujas Z. Diagnóstico de coccidias y microsporas en muestras de heces diarreicas de pacientes cubanos seropositivos al VIH:primer reporte de microsporas en Cuba. Rev Cuba Med Trop 2003;55: 14-8.

42. Estrella C, Valdez C, Luna E, Bustos C, Koch F. Relación entre parasitosis no habituales y valores de linfocitos T CD4 en pacientes de VIH/SIDA. Rev Med Tucuman 2001;7:81-90.

43. Mannheimer SB, Soave R. Protozoal infections in patients with AIDS. Cryptosporidiosis, isosporiasis, cyclosporiasis, and microsporidiosis. Infect Dis Clin North Am 1994;8:483-98.

44. Wilcox C. Diarrea en el paciente con SIDA. Gastroenterol Latinoam 2003;14:36-40.
45. Beltrán M, Ayala M. Evaluación externa de os resultados serológicas en los bancos de sangre de Colombia. Rev Panam Salud Pública 2003;13:138-43.

46. Acosta J, Prieto F, Rodríguez D, Rueda C. Situación de las enfermedades de transmisión sexual, Colombia, 1976-2000. Biomédica 2002;22:77-88.

47. Pérez F, Dabis F. HIV prevention in Latin America: reaching youth in Colombia. AIDS Care 2003;15:77-87.

48. Brasil P, de Lima DB, de Paiva DD, Lobo MS, Sodre FC, Silva SP et al. Clinical and diagnostic aspects of intestinal microsporidiosis in HIV-infected patients with chronic diarrhea in Rio de Janeiro, Brazil. Rev Inst Med Trop Sao Paulo 2000;42:299-304.

49. Hojlyng N, Nielsen A, Wandall J, Blom J, Molbak K, Chauhan $\mathrm{D}$ et al. First cases of microsporidiosis in Scandinavian patients with AIDS. Scand J Infect Dis 1993;25:667-9.

50. Miro O, Moreno A, Valls ME, Miro JM, Pique JM, Bordas JM et al. Microsporidiosis intestinal en pacientes con SIDA: estudio de 3 casos. Med Clin (Barc) 1995; 104:96-9.

51. Carlson SJ, Craig RM. Prevalence of intestinal microsporidiosis in HIV-infected individuals. Am J Gastroenterol 1995;90:1184-5.

52. Báez E, Arcay L, Reverand S, Otero E. Microspora: etiological agent in chronic diarrhoea. Bol Soc Venez Microbiol 2000;20:53-6.

53. Lee JH. Using pig biliary system, in vivo propagation of Enterocytozoon bieneusi, an AIDS-related zoonotic pathogen. J Vet Sci 2000;1:105-11.

54. Mathis A, Breitenmoser AC, Deplazes P. Detection of new Enterocytozoon genotypes in faecal samples of farm dogs and a cat. Parasite 1999;6:189-93.

55. Didier ES, Didier PJ, Snowden KF, Shadduck JA. Microsporidiosis in mammals. Microbes Infect 2000;2: 709-20.

56. Sobottka I, Albrecht H, Schottelius J, Schmetz C, Bentfeld M, Laufs R et al. Self-limited traveller's diarrhea due to a dual infection with Enterocytozoon bieneusi and Cryptosporidium parvum in an immunocompetent HIV-negative child. Eur J Clin Microbiol Infect Dis 1995;14:919-20.

57. Sandfort J, Hannemann A, Gelderblom H, Stark K, Owen RL, Ruf B. Enterocytozoon bieneusi infection in an immunocompetent patient who had acute diarrhea and who was not infected with the human immunodeficiency virus. Clin Infect Dis 1994;19:514-6.

58. Field AS. Light microscopic and electron microscopic diagnosis of gastrointestinal opportunistic infections in HIV-positive patients. Pathology 2002;34:21-35.

59. Moura H, Da Silva JL, Sodre FC, Brasil P, Wallmo K, Wahlquist $\mathbf{S}$ et al. Gram-chromotrope: a new technique 
that enhances detection of microsporidial spores in clinical samples. J Eukaryot Microbiol 1996;43:94S-5S.

60. Enriquez FJ, Ditrich O, Palting JD, Smith K. Simple diagnosis of Encephalitozoon sp. microsporidial infections by using a panspecific antiexospore monoclonal antibody. J Clin Microbiol 1997;35:724-9.

61. Moura H, Sodre FC, Bornay-Llinares FJ, Leitch GJ, Navin T, Wahlquist $\mathbf{S}$ et al. Detection by an immunofluorescence test of Encephalitozoon intestinalis spores in routinely formalin-fixed stool samples stored at room temperature. J Clin Microbiol 1999;37:2317-22.

62. Chukwuma C Sr. Microsporidium in AIDS patients: a perspective. East Afr Med J 1996;73:72-5.

63. Hunter PR, Nichols G. Epidemiology and clinical features of Cryptosporidium infection in immunocompromised patients. Clin Microbiol Rev 2002;15:14554.

64. Saksirisampant W, Eampokalap B, Rattanas-rithong M, Likanonsakul S, Wiwanitkit V, Nasingkarn A et al. A prevalence of Cryptosporidium infections among Thai HIV-infected patients. J Med Assoc Thai 2002;85: S424-8.

65. Zamudio ML, Aguilar JL, Frisancho O, Barreda R, Caballero P, Verano R. Parasitosis intestinal en pacientes infectados con el virus de la inmunodeficiencia humana. Bol Soc Perú Med Interna 1995;8: 13-9.

66. Zaraza C, Díaz L, Vargas L, Santos R, Sepúlveda J, Pinto $\mathbf{M}$ et al. Prevalencia de Cryptosporidium en muestras de materia fecal llevadas a diez laboratorios del área de Bucaramanga; Colombia. Med UIS 1994; 8:2-5.
67. Rincón de Heredia W, Calvo B, Acurero E, Chaparro $\mathrm{O}, \mathrm{Paz}$ M, Guanipa $\mathrm{S}$ et al. Prevalencia de parásitos intestinales en niños con diarrea atendidos en centros asistenciales de la ciudad de Maracaibo. Kasmera 1995; 23:27-41.

68. Sánchez A, Mora J, Hernández F. Prevalencia de parásitos intestinales en adultos mayores, Hospital Rául Blanco Cervantes. Rev Costarric Cienc Med 1999; 20:167-73.

69. López C, Moncada L, Murcia M, Saravia J, Nicholls RS. Frecuencia de parásitos intestinales en pacientes VIH+ en la ciudad de Santa Fe de Bogotá. Rev Fac Med UN Col 1999;47:9-12.

70. Mohandas K, Sehgal R, Archane S, Malla N. Prevalence of intestinal parasitic pathogen in HIVseropositive individualas in Northen India. Jpn J Infect Dis 2002;55:339-44.

71. Cimerman S, Cimerman B, Lewi DS. Prevalence of intestinal parasitic infections in patients with acquired immunodeficiency syndrome in Brazil. Int $\mathrm{J}$ Infect Dis 1999;3:203-6.

72. Mohindra AR, Lee MW, Visvesvara G, Moura H, Parasuraman R, Leitch GJ et al. Disseminated microsporidiosis in a renal transplant recipient. Transpl Infect Dis 2002;4:102-7.

73. Wanke CA, DeGirolami P, Federman M. Enterocytozoon bieneusi infection and diarrheal disease in patients who were not infected with human immunodeficiency virus: case report and review. Clin Infect Dis 1996;23:816-8.

74. Weiss LM. Microsporidia 2001: Cincinnati. J Eukaryot Microbiol 2001;48:(Suppl.):47S-49S. 